\title{
Reactive transport of Rare Earth Elements: surface complexation with quartz surfaces and modeling investigations
}

\author{
MUQEET IQBAI ${ }^{1}$, REMI MARSAC ${ }^{2}$ AND KHALIL \\ HANNA $^{3}$ \\ ${ }^{1}$ Université Rennes 1 - Geosciences Rennes \\ ${ }^{2}$ Géosciences Rennes - UMR CNRS 6118 \\ ${ }^{3}$ Institut des Sciences Chimiques de Rennes - UMR CNRS 6226 \\ Presenting Author: muqeet.iqbal448@gmail.com
}

Rare Earth Elements (REE) are not only considered as hightechnology components but also as contaminants of emerging concern creating long-term ecological effects when released into ecosystems. However, there is a lack of comprehensive investigations on their mobility, environmental fate and transport in geochemical settings. In addition, most of the previous studies reported adsorption of one or a few REE onto minerals, and knowledge on dynamic changes of the entire REE patterns in natural porous media is scarce. Here, we have thoroughly examined the interactions of the entire REE group with 100-300 $\mu \mathrm{m}$ quartz sand particles under water-saturated flow conditions. Both batch and dynamic column experiments are conducted at environmentally relevant geochemical conditions.

Adsorption of REE on the quartz surface was investigated over a wide range of $\mathrm{pH}$ and varying $\mathrm{REE}$ concentrations. As typically encountered for cations, REE binding increased with increasing $\mathrm{pH}$ values. Results from batch experiments showed that there is a stronger adsorption for middle REE as compared to light REE or heavy REE. A surface Complexation Model (SCM) based on inner-sphere coordination with silanol groups has been developed for quartz sand, which successfully predicted both sorption edges and sorption isotherms.

We also observed the REE competitive binding in the column experiments where the middle REE are preferentially adsorbed compared to the light and heavy REE. Tracer experiments showed that a homogeneous flow predominates in the sandpacked column. We then developed a transport model using batch-derived surface complexation constants and flow parameters, which account for physical and chemical processes in the column system. This combined model can well describe the breakthrough curves of REE in sand columns under various hydrochemical conditions. These results have strong implications for an accurate assessment of the transport behavior of REEs in natural systems. 